\title{
World Scientific Lecture Notes
}

in Complex Systems - Vol. 8

editors

TheAstralian National University, Australia

T Di Matteo

TheAustralian National University, Australia

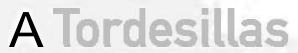

University of Melbourne, Australia

\section{Granular and
Complex Materials \\ Granular and
Complex Materials}


Published by

World Scientific Publishing Co. Pte. Ltd.

5 Toh Tuck Link, Singapore 596224

USA office: 27 Warren Street, Suite 401-402, Hackensack, NJ 07601

UK office: 57 Shelton Street, Covent Garden, London WC2H 9HE

\section{British Library Cataloguing-in-Publication Data}

A catalogue record for this book is available from the British Library.

\section{GRANULAR AND COMPLEX MATERIALS}

Copyright ( 2007 by World Scientific Publishing Co. Pte. Ltd.

All rights reserved. This book, or parts thereof, may not be reproduced in any form or by any means, electronic or mechanical, including photocopying, recording or any information storage and retrieval system now known or to be invented, without written permission from the Publisher.

For photocopying of material in this volume, please pay a copying fee through the Copyright Clearance Center, Inc., 222 Rosewood Drive, Danvers, MA 01923, USA. In this case permission to photocopy is not required from the publisher.

ISBN-13 978-981-277-198-8

ISBN-10 981-277-198-0 
Dedicated to Francesca and Carmel

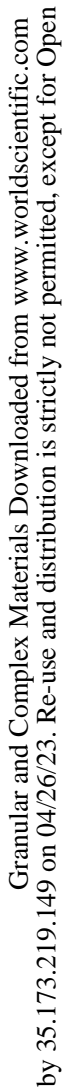


This page intentionally left blank

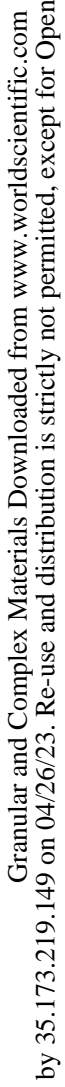




\section{Preface}

The Science of Complex Materials is attracting an ever increasing interest and participation of researchers from a vast range of disciplines, including physics, mathematics, computational science, and virtually all domains of engineering. These lecture notes present invited lectures and selected contributions from the $20^{\text {th }}$ Canberra International Physics Summer School and Workshop on Granular Materials, held at The Australian National University in Canberra, between the 4th and the 8th of December 2006. At the meeting, international experts from 21 different countries gathered together to debate and discuss the latest advances in the experimental, computational and mathematical analysis of granular materials and other related complex materials such as foams, porous media and cellular solids. The contributions in these Lecture Notes explore an array of problems reflecting recent developments in four main areas:

- Characterisation and Modelling of Disordered Packings;

- Micromechanics and Continuum Theory;

- Discrete Element Method;

- Statistical Mechanics.

The common theme and, indeed, the driving force behind these investigations is the quest to unravel the connection between the microscopic and the macroscopic properties of complex materials.

The microscopic structural properties of complex materials and disordered packings are introduced in the contribution by Weaire et al. which highlights intriguing similarities between granular materials and foams. An old unsolved question, "Why spheres poured in a container never pack denser than $64 \%$ of the total volume?" is addressed in an 
innovative way by Anikeenko et al. by introducing a set of geometrical tools to understand, classify and characterize the structure of disordered packings. Structural characterization of granular materials is also discussed in the contribution of Blumenfeld by using innovative entropic approaches.

New techniques that have recently emerged from novel amalgams of established methodologies in mechanics are explored in several contributions. Vardoulakis et al. present a study that adapts "shallow water theory" to granular flows. Einav develops a new continuum theory on particle comminution in brittle granular materials by using thermomechanics and statistical mechanics. Tordesillas presents a novel continuum formulation that delivers constitutive laws expressed entirely in terms of particle scale properties by weaving together principles and techniques from thermodynamics, micromechanics, structural mechanics and micropolar theory. The contribution by Tejchman et al. explores size effects in finite element continuum simulations by using stochastic techniques. These continuum formalisms rely heavily on particle scale information. For this purpose, the effectiveness of discrete element method (DEM) remains unsurpassed. The contribution by Cleary shows what can be achieved in DEM simulations for industrial and geophysical applications, particularly in the areas of mixing, separation, excavation, comminution, storage, transport and sampling of granular materials. The contribution from Delaney et al. discusses cutting-edge developments in DEM combined with x-ray computer tomography to perform 'virtual experiments'.

The contribution by Behringer provides an overview of granular properties, with a particular focus on the dense granular states. An exploration of a range of phenomena, from force chains to non-affine motion, is illustrated through a series of experiments. These studies deliver new insights on the role of fluctuations at the microscopic and mescoscopic levels. Fluctuations are also the core of the contribution by Nicodemi et al. where a statistical mechanics approach that enables us to predict such fluctuations is constructed. An experimental validation of such an extension of thermodynamics to non-thermal systems is discussed in the contribution by Richard et al. where the dynamics of granular media submitted to gentle mechanical tapping is studied. These 
studies are crucial to understand the properties of stationary states and discuss the validity of such configurations as genuine 'thermodynamic' states.

In conclusion, this volume presents a unique multidisciplinary panorama of the current research in complex materials. Our aim is to encourage open interdisciplinary discussions between physicists, engineers, mathematicians and computer scientists, in order to develop a common language and achieve complementary objectives.

Tomaso Aste

Antoinette Tordesillas

Tiziana Di Matteo

Editors 


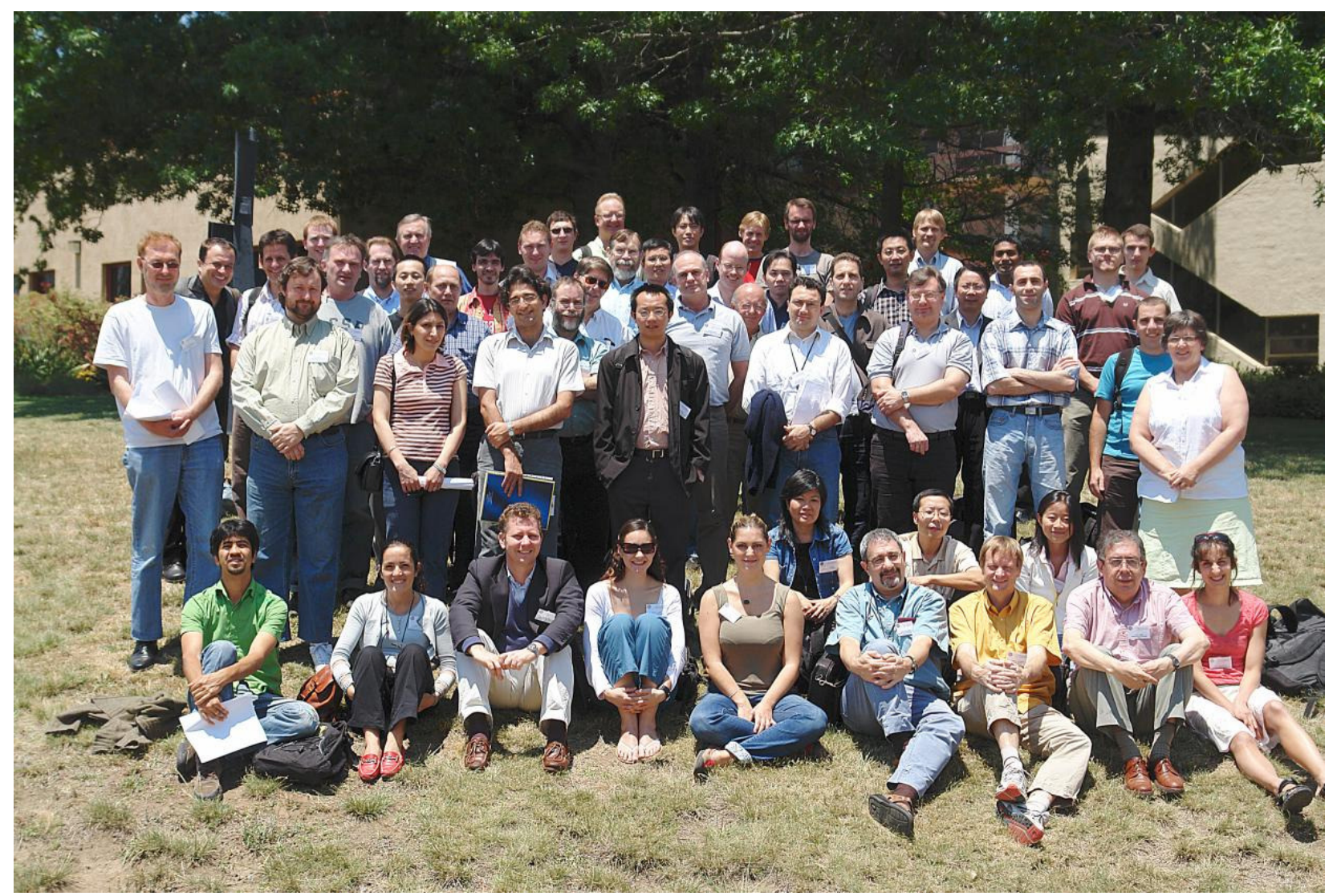




\section{Contents}

Preface vii

$\begin{array}{lll}\text { Chapter } 1 & \text { Foam as granular matter } & 1\end{array}$

D. Weaire, V. Langlois, M. Saadatfar and S. Hutzler

Chapter 2 Delaunay simplex analysis of the structure of equal sized spheres
A.V. Anikeenko, N.N. Medvedev, T. Di Matteo, G.W. Delaney and T. Aste

Chapter 3 On entropic characterization of granular materials

R. Blumenfeld

Chapter 4 Mathematical modeling of granular flow-slides

I. Vardoulakis and S. Alevizos

Chapter 5 The mechanics of brittle granular materials

\section{Einav}

Chapter 6 Stranger than friction: force chain buckling and its implications for constitutive modelling
A. Tordesillas

Chapter 7 Investigations of size effects in granular bodies during plane strain compression

J. Tejchman and J. Górski 
Chapter 8 Granular flows: fundamentals and applications P.W. Cleary

Chapter 9 Fine tuning DEM simulations to perform virtual experiments with three-dimensional granular packings

G.W. Delaney, S. Inagaki and T. Aste

Chapter 10 Fluctuations in granular materials R.P. Behringer

Chapter 11 Statistical mechanics of dense granular media M. Pica Ciamarra, A. de Candia, A. Fierro, M. Tarzia, A. Coniglio and M. Nicodemi

Chapter 12 Compaction of granular systems P. Richard, F. Lominé, P. Ribière, D. Bideau and $R$. Delannay 